\title{
Role of HRCT Temporal Bone In Patients with Chronic Supparative Otitis Media
}

\author{
Hiral Happani ${ }^{1}$, Jagruti Kalola ${ }^{2}$, Hiren Rathod ${ }^{3}$, Anjana Trivedi ${ }^{4}$ \\ ${ }^{1}$ Assistant Professor, ${ }^{2}$ Associate Professor, ${ }^{3} 3$ rd Year Resident, ${ }^{4}$ Head of Department, Department of Radiology, PDU MC, \\ Rajkot, India
}

Corresponding author: Hiren Rathod, Room No 321, New PG Hostel, Near Ruda Building, PDU MC, Rajkot 360001, India

DOI: 10.21276/ijcmsr.2018.3.3.15

How to cite this article: Hiral Happani, Jagruti Kalola, Hiren Rathod, Anjana Trivedi. Role of HRCT temporal bone in patients with chronic supparative otitis media. International Journal of Contemporary Medicine Surgery and Radiology. 2018;3 (3):C70-C72.

\section{A B S T R A C T}

Introduction: Chronic suppurative otitis media (CSOM) is inflammation of middle ear of greater than two weeks that results in ear discharge. It is associated with hearing loss. The role of HRCT temporal bone comes in the knowing the extent of involvement caused by the disease.

Material and Methods: The study was done on 50 patients diagnosed clinically with CSOM between December 2017 to May 2018 with the help of GE Bright Speed 16 slice machine.

Results: Out of 50 patients 32 were males and 18 were females. Cholesteatoma was found in 29 patients, followed by ear ossicle erosion (22 patients), mastoditis (15 patients),tympanic membrane perforation (6 patients), labyrinthine fistula (3 patients) and malignancy (2 patient).

Epitympanum was involved in 29 patients followed by antrum (28 patients), mastoid air cells (22 patients),aditus (19 patients), mesotympanum (12 patients), hypotympanum (12 patients),perilabyrinthine cells (5 patients).

Amonst the complicated cases, brain abscess was found in 4 patients followed by mastoid abscess ( 2 patients), labyrinthine fistula (1patient),facial nerve palsy (1 patient) and meningitis (1 patient).

Conclusions: HRCT of temporal bone is useful in finding the location and extent of disease in patients with chronic supparative otitis media. It is of great importance in guiding the surgeon to plan for appropriate surgical approach as well as in conservative management.

Key words: Chronic Suppurative Otitis Media (CSOM), Cholesteatoma, HRCT of Temporal Bone.

\section{INTRODUCTION}

Chronic suppurative otitis media (CSOM) is an inflammation of middle ear of greater than two weeks that results in ear discharge. It is associated with hearing loss. Pain is usually not present. Bacteria as well as viral agent may be responsible. People with poor eustachian tube function, with history of multiple episodes of acute otitis media, living in crowded conditions, and attending pediatric day care facilities are at increased risk. People with craniofacial malformations such as cleft lip and palate, Down syndrome, and microcephaly are also at higher risk.

An upper respiratory tract infection leads to acute otitis media which progresses to a prolonged inflammatory reaction which leads to middle ear mucosal edema, ulceration and thereby perforation. Ulceration may get resolved by production of granulation tissue and polyp formation which may lead to increased discharge. Failure to arrest the inflammation and to development of CSOM is associated with cholesteatoma formation. Excess Pus drains to the outside of the ear (otorrhea), or there may be minimal pus enough to be seen only on examination with an otoscope or binocular microscope.
HRCT has a significant impact on the medical and surgical management of patients with middle ear disease. It confirms otoscopic findings to greater extent, clear many clinical doubts, and helps in determining surgical efficacy when surgery will be necessary and also for planning the approach for surgery. However, routine HRCT scanning prior to all surgery of cholesteatoma can only be justified if it can be shown to influence clinical management.

The present study aims at studying the radiological findings of the temporal bone in patients with CSOM, to look at extent and sites of involvement of the middle ear and the mastoid air cells, to look for complications of CSOM (if any) and to establish role of HRCT temporal bone in medical as well as surgical management of patients with Chronic suppurative otitis media (CSOM).

\section{MATERIAL AND METHODS}

The present study was conducted on 50 patients who were clinically diagnosed with Chronic suppurative otitis media (CSOM) and sent to radiology department of Pandit Deendayal Upadhyay medical college, Rajkot between the months of December 2017 to May 2018. Study was done after ethical approval and informed consent. Each patient 
underwent HRCT temporal bone. CT scan was done with GE Bright Speed 16 slice machine. Plain HRCT imaging of temporal bone was performed using submillimeter thin contiguous axial scan. Reformatted images were obtained and reviewed. Intravenous contrast was used only when indicated to look for complications of the infective process. CT brain was done only in patients with suspected neurological complications. Reporting was done by a single consultant radiologist with expertise in reading HRCT temporal bone.

\section{STATISTICAL ANALYSIS}

Statistical analysis was done using Microsoft office plus 2016. Patients affected with different levels of involvement by disease were identified and percentage obtained.

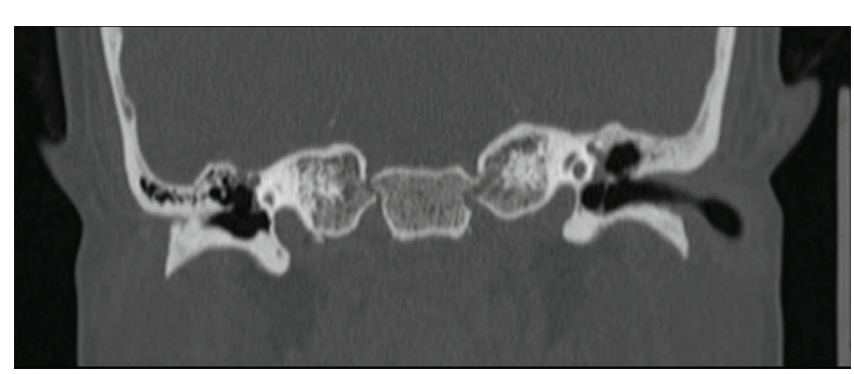

Figure-1: Soft tissue density lesion is noted in the epitympanum suggesting left side cholesteatoma formation.

\begin{tabular}{|l|c|c|}
\hline Findings & $\begin{array}{c}\text { No of } \\
\text { patients }\end{array}$ & Percentage \\
\hline Cholestetoma & 29 & 58 \\
\hline Mastoditis & 15 & 30 \\
\hline Tymphanic membrane perforation & 6 & 12 \\
\hline Ear ossicles erosin & 22 & 44 \\
\hline Labyrinthine fistula & 3 & 6 \\
\hline Malignancy & 2 & 4 \\
\hline Normal & 1 & 2 \\
\hline \multicolumn{2}{|c|}{} \\
\hline
\end{tabular}

\begin{tabular}{|l|c|c|}
\hline Site of involvement & No of patients & Percentage \\
\hline Epitympanum & 29 & 58 \\
\hline Mesotypanum & 12 & 24 \\
\hline Hypotypanum & 12 & 24 \\
\hline Perilabyrinthine cells & 5 & 10 \\
\hline Aditus & 19 & 38 \\
\hline Antrum & 28 & 56 \\
\hline Mastoid air cells & 22 & 44 \\
\hline \multicolumn{2}{|c|}{ Table-2: Site of involvement } \\
\hline
\end{tabular}

\begin{tabular}{|l|c|c|}
\hline & No of patients & Percentage \\
\hline Extracranial complications \\
\hline Mastoid abscess & 2 & 4 \\
\hline labyrinthine fistula & 1 & 2 \\
\hline Facial nerve palsy & 1 & 2 \\
\hline Intracranial complications \\
\hline Brain abscess & 4 & 8 \\
\hline Meningitis Table-3: Complications \\
\hline \multicolumn{2}{|c|}{} \\
\hline
\end{tabular}

\section{RESULTS}

Out of 50 patients, the age at presentation ranged from 1 year to 60 years. The mean age was 30 years and the most commonly affected age group ranged 31 to 45 years. In this study CSOM was found slightly more common in males (64\%) than females (36\%). Right ear was effected in 22 patients (44\%), left ear was effected in 18 patients (36\%) and 10 patients $(20 \%)$ showed bilateral involvement. Most of the patients were of low socioeconomic status (80\%) and presented with a long standing neglected ear discharge. Complications were found in 9 patients (18\%) out of which 5 developed intracranial complications (10\%) and 4 developed extra cranial complications (8\%). The result obtained is displayed in table 1 to 3 .

\section{DISCUSSION}

In this study, male: female ratio was 1.7:1 which is in accordance with the study by Kemppainen et al ${ }^{1}$. The most common presenting symptom was Otorrhoea which was followed by hearing loss and otalgia. Many patients presented with fever, tinnitus, vertigo, nausea, vomiting, and facial nerve palsy. This indicates that many patients were unaware of the disease and come to hospital relatively late and delayed the initial treatment. It was observed that right ear was more commonly infected than left and only few patients showed bilateral involvement (figure 1). Cholesteatoma was the most commonly encountered finding in patients with CSOM (table-1). Ossicular erosion was noted in most cases of $\mathrm{CSOM}$ associated with cholesteatoma. Though there is slight variation in the incidence of erosion of each ossicle seen in different studies, in our study it was identified that incus is the most commonly involved ossicle, than malleus which was followed by stapes. Also involvement of one or more ossicle is associated with the severity of disease process and is a poor prognostic factor. Mastoditis was the next most common finding in our study (table-1). Lateral semicircular canal erosion was seen in 1 case (out of 3 cases with labyrinthine fistula) which is similar to study by O'Reilly BJ et al. $7^{7}$ and Petros V.Vlastarakos et al. $4^{3}$.

Malignancy was found only in 2 patients (4\%) and both belong to age group of $>60$ years suggesting a relatively lower incidence. One of the patient in the study had completely normal HRCT temporal bone which was supposed to be due to early presentation.

Regarding the site of involvement it was found that epitympanum was most commonly involved (29 patients), followed by antrum (28 patients),then mastoid air cells (22 patients), aditus (19 patients), mesotypanum and hypotypanum (12 patients) and lastly perilabyrinthine cells (5 patients) (table-2).Post operative follow up were taken in patients and the site of involvement as described in report of HRCT temporal bone was accurately correlated with intraoperative findings in 48 patients (96\%).

Only 9 patients out of 50 (18\%) developed complications related to CSOM. Most of this patients belonged to poor socioeconomic status who delayed the diagnosis and treatment due to one or the other reason there by leading to development of complications. Most of the complicated 
patients (7 out of 9 , ie 77\%) belonged to age group of 20-30 years indicating a higher incidence in young adults. 8 out of $9(88 \%)$ were males indicating that males predominately developed complications. Based on history it was found that males were more involved due to swimming in local pools in our area and it is associated with higher incidence of complications in male population in our study group.

Also amongst the complicated patients it was found that intracranial complications developed in 5 patients $(55 \%$ of the complicated patients) and 4 patients developed Extracrainal complication ( $45 \%$ of the complicated patients) indicating that intracranial complications are more common than extracranial complictions (table-3). This was in accordance to the study by E. Yorgancilar et $\mathrm{al}^{4}$. Amongst the intracranial complications brain abscess ( $44 \%$ of all complicated patients) was more commonly found than meningitis $(11 \%$ of all complicated patients). Other intracranial complications like Lateral sinus thrombophlebitis, Extradural abscess, Subdural empyema etc were not noticed in our study. While amongst the extracrainal complications mastoid abscess was found in 2 patients (22\% of all complicated patients) followed by development of labyrinthine fistula and facial nerve palsy noted in $11 \%$ of all complicated patients.

\section{CONCLUSION}

CSOM is a common disease with some serious life threatening complications. Early diagnosis and treatment is of importance for a good patient outcome. HRCT of temporal bone plays a great role in the diagnosis and preoperative assessment of patients with CSOM. CSOM is more common in the younger age group with a slight male predominance. Oterrhoea is the most common symptom. Patients may present with other symptoms like fever,hearing loss, otalgia, vertigo, tinnitus, headache, nausea, vomiting, swelling behind the ear and facial weakness. Ossicular erosion is often present in patients of CSOM with cholesteatoma. Incus is the most commonly involved ossicle, followed by malleus and stapes. Brain abscess is the most common complication, followed by mastoid abscess followed by labyrinthine fistula,meningitis and facial nerve palsy. Cholesteatoma is the most common finding in patients with CSOM. The various other findings observed in the patients with CSOM includes ossicular erosion,tympanic membrane perforation and soft tissue density lesions(neoplastic). HRCT of temporal bone is useful in findings the location and extent of disease in patients with chronic supparative otitis media and is of great importance in guiding the surgeon to plan for appropriate the surgical approach as well as in deciding when to keep the patient on conservative treatment.

\section{REFERENCES}

1. Kemppainen, Heikki O., et al. Epidemiology and aetiology of middle ear cholesteatoma. Acta otolaryngologica 1999;119(5): 568-572.

2. Kangsanarak J, Fooanant S, Ruckphaopunt K, Navacharoen N, Teotrakul S. Extracranial and intracranial complications of suppurative otitis media: report of 102 cases. J Laryngol Otol 1993; 107 (5):999_ 1004.
3. Petros V Vlastarakos, Catherine Kiprouli, Sotirios Pappas, John Xenelis, Paul Maragoudakis, George Troupis, et al. CT scan versus surgery: how reliable is the preoperative radiological assessment in patients with chronic otitis media? Eur Arch Otorhinolarynogol 2012;269(3):81- 6 .

4. Yorgancilar, E., et al. "Complications of chronic suppurative otitis media: a retrospective review." European Archives of Oto-Rhino-Laryngology 2013;27(1): 69-76

5. Vavassori GE. Imaging of temporal bone. In: Clinical Evaluation, Glasscock-Shambaugh Surgery of the Ear. $5^{\text {th }}$ ed., Ch. 11, Part 2 Section 2. Shelton, Connecticut: Pmph USA; 2003. p. 227-33.

6. Vavassori GE, Hemmati M. Imaging of the temporal bone In: Clinical Evaluation and Rehabilitation, Glasscock-Shambaugh Surgery of the Ear. $6^{\text {th }}$ ed., Ch. 13, Section 2. Shelton, Connecticut: Pmph USA; 2012. p. 255-67. [2010 May 15]

7. O'Reilly BJ, Chevretton EB, Wylie I, Thakkar C, Butler $\mathrm{P}$, Sathanathan N, et al. The value of CT scanning in chronic suppurative otitis media. J Laryngol Otol 1991;105 (1):990-4.

8. Garber LZ, Dort JC. Cholesteatoma: Diagnosis and staging by CT scan. J Otolaryngol 1994;23 (3):121-4.

9. Sirigiri RR, Dwaraknath K. Correlative Study of HRCT in Attico-Antral Disease. Indian J Otolaryngol Head Neck Surg 2011;63 (6):155-8.

Source of Support: Nil; Conflict of Interest: None

Submitted: 01-07-2018; Accepted: 02-08-2018; Published online: 13-08-2018 